\title{
Use of Occupancy Models to Evaluate Expert Knowledge-based Species- Habitat Relationships
}

\section{Utilisation de modèles de présence pour évaluer les relations espèces- habitat fondées sur les connaissances d'experts}

\author{
Monica N. Iglecia ${ }^{1}$, Jaime A. Collazo $^{2}$ and Alexa J. McKerrow ${ }^{3}$
}

\begin{abstract}
Expert knowledge-based species-habitat relationships are used extensively to guide conservation planning, particularly when data are scarce. Purported relationships describe the initial state of knowledge, but are rarely tested. We assessed support in the data for suitability rankings of vegetation types based on expert knowledge for three terrestrial avian species in the South Atlantic Coastal Plain of the United States. Experts used published studies, natural history, survey data, and field experience to rank vegetation types as optimal, suitable, and marginal. We used single-season occupancy models, coupled with land cover and Breeding Bird Survey data, to examine the hypothesis that patterns of occupancy conformed to species-habitat suitability rankings purported by experts. Purported habitat suitability was validated for two of three species. As predicted for the Eastern Wood-Pewee (Contopus virens) and Brown-headed Nuthatch (Sitta pusilla), occupancy was strongly influenced by vegetation types classified as "optimal habitat" by the species suitability rankings for nuthatches and wood-pewees. Contrary to predictions, Red-headed Woodpecker (Melanerpes erythrocephalus) models that included vegetation types as covariates received similar support by the data as models without vegetation types. For all three species, occupancy was also related to sampling latitude. Our results suggest that covariates representing other habitat requirements might be necessary to model occurrence of generalist species like the woodpecker. The modeling approach described herein provides a means to test expert knowledge-based species-habitat relationships, and hence, help guide conservation planning.
\end{abstract}

RÉSUMÉ. Les relations espèces-habitat établies à partir des connaissances d'experts sont largement utilisées pour orienter la planification de la conservation, surtout lorsque les données sont rares. Ces relations présumées représentent les rudiments de la connaissance, mais sont rarement testées. L'adéquation du classement de milieux établi par des experts a été évaluée pour trois espèces de passereaux de la Plaine côtière de l'Atlantique Sud, aux États-Unis. Les experts ont utilisé des données publiées (recherches, histoire naturelle, relevés) et leur expérience sur le terrain afin de classer les milieux selon trois catégories, soit optimaux, adéquats ou marginaux. Nous avons appliqué des modèles de présence, fondés sur une seule saison, à des données d'occupation du sol et de relevés d'oiseaux nicheurs afin d'examiner l'hypothèse voulant que les profils de présence concordent avec le classement de la qualité des milieux présumé par les experts. La qualité présumée des milieux a été validée pour deux des trois espèces. Comme prédit pour le Pioui de l'Est (Contopus virens) et la Sittelle à tête brune (Sitta pusilla), la présence de l'espèce s'est révélée fortement liée aux milieux classés comme « optimaux » pour les sittelles et les piouis. Contrairement aux prédictions pour le Pic à tête rouge (Melanerpes erythrocephalus), les modèles qui incluaient les milieux comme covariables étaient équivalents aux modèles qui ne les incluaient pas. Chez les trois espèces, la présence était aussi corrélée à la latitude de l'échantillonnage. Nos résultats semblent indiquer qu'il serait peut-être nécessaire d'inclure des covariables relatives à d'autres besoins en matière d'habitat afin de modéliser la présence d'espèces généralistes comme le pic. L'approche de modélisation décrite dans cette étude permet de tester les relations espèces-habitat établies d'après les connaissances d'experts et, par conséquent, contribue à orienter la planification de la conservation.

Key Words: Breeding Bird Survey; Brown-headed Nuthatch; Eastern Wood-Pewee; expert knowledge; habitat conservation; Red-headed Woodpecker; South Atlantic Coastal Plain

\footnotetext{
${ }^{1}$ Audubon California, Migratory Birds Program, ${ }^{2}$ U.S. Geological Survey, North Carolina Cooperative Fish and Wildlife Research Unit, ${ }^{3} \mathrm{U}$. S. Geological Survey, Biodiversity and Spatial Information Center, North Carolina State University
}

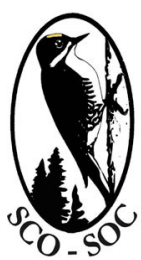

Sponsored by the Society of Canadian Ornithologists and Bird Studies Canada Parrainée par la Société des ornithologistes du Canada et Études d'oiseaux Canada

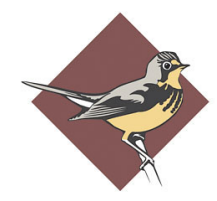




\section{INTRODUCTION}

Expert knowledge-based species-habitat relationships are used extensively in conservation planning, partly because data for most species are usually scarce, or limited resources prevent collecting data in time to meet conservation challenges (Drew and Perera 2011, Drew and Collazo 2012). Experts draw from their observations, readings, discussions, and other means, and offer opinions or specific knowledge about ecological patterns and processes (Perera et al. 2012). The purported species-habitat relationships from these experts are viewed as working hypotheses that serve as priors describing the initial state of knowledge, but are rarely tested empirically (Clevenger et al. 2002, Johnson and Gillingham 2004, Low-Choy et al. 2009, Schlossberg and King 2009, Johnson et al. 2012). Tests are of interest because planners and decision makers draw from this initial state of knowledge to draft conservation plans and predict a species' response to conservation actions (e.g., Clevenger et al. 2002, Zabel et al. 2003, Low-Choy et al. 2009, Allen et al. 2011).

Hamel (1992) categorized vegetation types in southeastern United States according to their suitability for terrestrial avian species. Suitability was ranked as optimal, suitable, and marginal based on avian abundance and occurrence. Suitability rankings were based on published studies, natural history, survey data, expert opinion, and field experiences (Hamel et al. 1982, Hamel 1992). As such, Hamel's expert opinion was founded on synoptic knowledge (Perera et al. 2012). Hamel's (1992) ranked vegetation types serve as guidelines for habitat conservation planning in the South Atlantic Coastal Plain of the United States. This region provides nesting, transient, and wintering habitat for over 300 bird species, but many are exhibiting declining population trends (Ricketts et al. 1999, Watson and McWilliams 2005, Watson and Malloy 2006, Valiela and Martinetto 2007). Approximately $40 \%$ of the region's natural vegetation communities have been fragmented or altered by human use, and it is believed this landscape change is a major contributor of population declines (Hunter et al. 2001). The rapidly expanding list of species of conservation priority in this region has placed increasing pressure on limited conservation resources, and additionally, on the need to inform conservation planning to formulate landscapescale conservation strategies (USFWS 2008).

In this work we used occupancy models, coupled with Breeding Bird Survey (BBS) and land cover data, to test hypothesized species-habitat relationships based on expert knowledge. Specifically, we asked, do patterns of occupancy conform to purported suitability rankings of vegetation types for avian species advanced by Hamel (1992) for the South Atlantic Coastal Plain? We illustrated the application of occupancy models to meet the stated objective using the Brown-headed Nuthatch (Sitta pusilla), Eastern WoodPewee (Contopus virens), and Red-headed Woodpecker
(Melanerpes erythrocephalus). These species are considered priority species in the coastal plain, and are sampled by Breeding Bird Surveys across the region (NCWRC 2005, Watson and Malloy 2006). Models were built with the Southeastern Gap Analysis Program (SEGAP) dataset, which is comprised of 118 land cover classes. The SEGAP dataset permitted grouping vegetation types into the three habitat suitability categories, i.e., optimal, suitable, and marginal, advanced by Hamel (1992).

Occupancy models accounted for imperfect detection of a species (MacKenzie et al. 2006). Estimates of occupancy without adjusting for imperfect detection $(<1)$, often referred to as naïve estimates, tend to be biased low because individuals present at a sampling site can go undetected (MacKenzie et al. 2002). This problem could affect inferences from specieshabitat models because the state, occupied or not, of a sampling site could be misrepresented, and by extension, the strength of or influence of a habitat covariate (MacKenzie et al. 2002, MacKenzie 2006). We also incorporated recent advances that account for spatial dependence among count stops along BBS routes as a means to strengthen inferences from models (Hines et al. 2010). We discuss the importance of testing expert knowledge-based species-habitat relationships in the context of landscape level conservation and suggest opportunities to strengthen inferences from occupancy models for such tests.

\section{METHODS}

\section{Study area}

Our study area was the South Atlantic Coastal Plain, specifically the South Atlantic Migratory Bird Initiative region (henceforth SAMBI). This is a physiographic area of high avian species diversity (Watson and McWilliams 2005). The region intersects portions of the Middle Atlantic Coastal Plain, Southeastern Plains, and the Southern Coastal Plain ecoregions (Omernik 1987), and spans from southeastern Virginia at the watershed boundary of the Chowan and Lower James rivers to northern Florida (latitudes $29^{\circ}-37^{\circ} \mathrm{N}$; Fig. 1). The northern portion of the region is dominated by longleaf pine (Pinus palustris) and loblolly pine (Pinus taeda). The SAMBI is bounded on its western edge at the Fall Line where alluvial and marine sediments meet the exposed continental bedrock of the Piedmont region (Hupp 2000) and on the eastern edge by the Atlantic Ocean. The southern SAMBI is in a transitional zone of northeastern Florida where tropical mangroves meet coastal plain plant communities; this region is dominated by pond pine (Pinus serotina) and Atlantic white cedar (Chamaecyparis thyoides; Watson and McWilliams 2005). We buffered the SAMBI boundary by $30 \mathrm{~km}$ to avoid edge effects and to encompass the habitats surrounding BBS routes that straddle the limits of the region. The total area of the buffered SAMBI is 29,073,338 ha with 2,606,020 ha of water and elevation ranges from $0 \mathrm{~m}$ to $219 \mathrm{~m}$. 
Fig. 1. Location of 120 North American Breeding Bird Survey routes used in occupancy modeling for three avian species in the South Atlantic Coastal Plain region, United States, 2001.

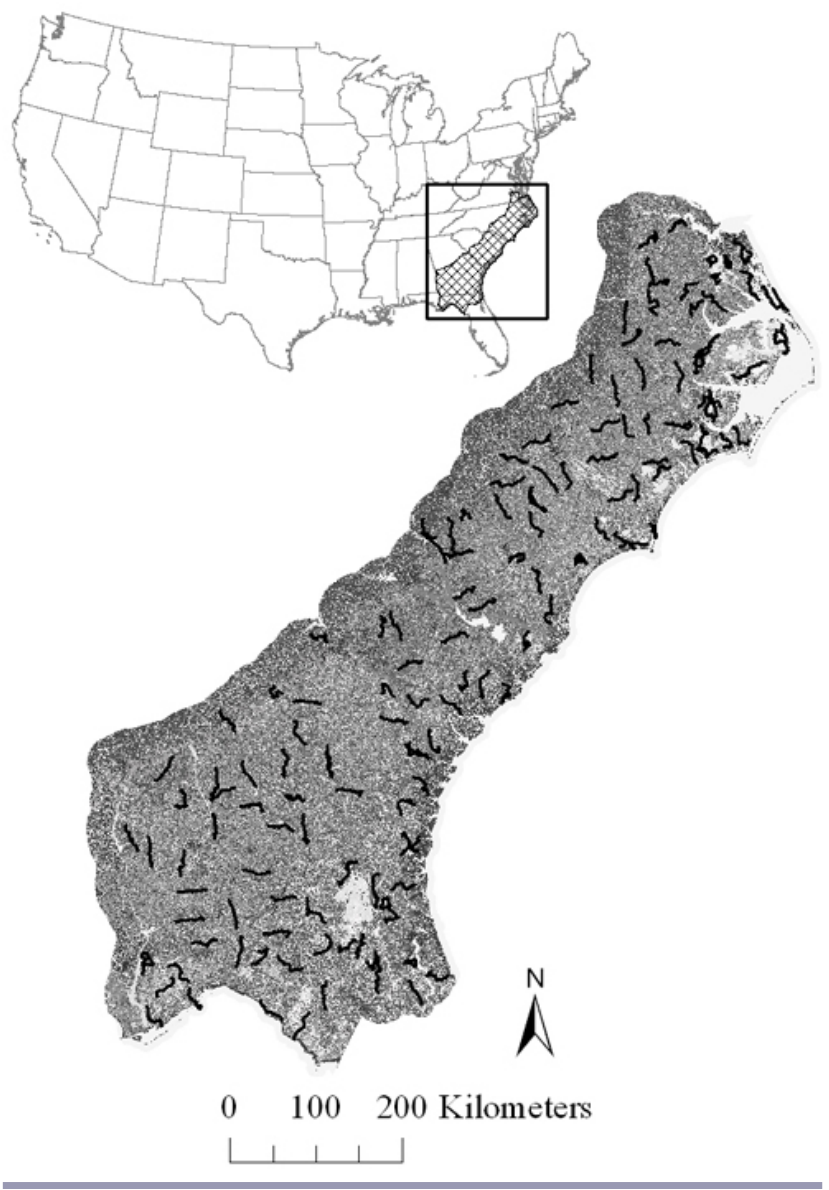

\section{Avian species}

The Brown-headed Nuthatch (hereafter nuthatch) is an endemic, resident species in the southeastern United States. The species ranges from eastern Texas to Florida and northward to the southern tip of Delaware (Withgott and Smith 1998). Nuthatches are commonly found in southeastern pine forests, especially open longleaf pine savannas in the coastal plain (Potter et al. 1980). Increased fire suppression increases growth of deciduous trees and shrubs, and in turn fills open understories that may make forests unsuitable for the species (Meyers and Johnson 1978, Smith and Smith 1994). This passerine excavates nests in the cavities of snags, dead pine trees, and some deciduous trees (McNair 1984, Kaufman 1996). The Red-headed Woodpecker (hereafter woodpecker) is a short-distance migrant that occurs in eastern United States (Smith et al. 2000). This species uses a diverse range of vegetation types including grasslands, shrubs, deciduous and evergreen forests, and inhabits evergreen forests more often than in other portions of its range (Smith et al. 2000). The woodpecker is an omnivore, but population densities and migration are closely related to acorn mast abundance (Forbush 1927). The woodpecker is a primary cavity nester, creating tree cavities beneficial to multiple vertebrate species (Venables and Collopy 1989). The Eastern Wood-Pewee (hereafter woodpewee) is a neotropical migrant that is commonly found in the interior of forests throughout eastern North America (Robbins et al. 1989). The breeding distribution for this species ranges from southern Canada to central Texas and northern Florida (McCarty 1996). Although the species most often inhabits deciduous forests, it increasingly inhabits evergreen forest types in the southern United States (McCarty 1996).

\section{Avian survey data and land cover}

We used North American BBS data from 2001 to address the question of interest in this study. BBS data are available from 1966; however, we analyzed avian survey data collected in 2001 to correspond with the only year for which SEGAP data were available. The Breeding Bird Surveys is a national, standardized, volunteer-based survey, with over 4000 routes sampling breeding birds across North America each year (Flather and Sauer 1996). Each route is $\sim 39.4 \mathrm{~km}$ long, composed of 50 stops spaced $\sim 0.8 \mathrm{~km}$ apart. Observers conduct three-minute point counts at each stop, recording all birds seen and heard within a $400 \mathrm{~m}$ radius. We included routes in the analyses if: (1) route lengths were within $10 \%$ of the standard $39.4 \mathrm{~km}$ length, and (2) routes did not overlap other active routes. This screening yielded 120 of 130 possible routes in the SAMBI (Fig. 1). We split each route into four segments containing eight stops each. We split routes based on two criteria, with the goal of maximizing both the number of segments per route and number of stops per segment. First, distance between adjacent segments had to be $\geq 4.73 \mathrm{~km}$. This distance falls between the $90-95 \%$ natal dispersal distance for the focal species, which meant that there was a 5-10\% probability that an individual of any of the three species would disperse farther (Sutherland et al. 2000, Iglecia 2010). Second, segments had to minimize habitat heterogeneity. On average, route segments had fewer habitat classes $(14.20, \mathrm{SE}=0.37)$ than entire BBS routes $\left(16.15, \mathrm{SE}=0.45 ; \mathrm{Z}_{20}=14.92, \mathrm{P}<\right.$ 0.05 ). These criteria yielded four route segments per route that were each $\sim 6.4 \mathrm{~km}$ long, containing eight stops in each, and separated by $\sim 4.8 \mathrm{~km}$. The gap between segments contained five stops, not used in the analyses. The segmentation of the routes also required that we drop three more stops from the analyses; the first and last stop and a stop close to the middle of each route. We treated segments separated by $\geq 4.73 \mathrm{~km}$ as independent sampling units.

The SEGAP dataset permitted matching vegetation types highlighted by Hamel (1992) to vegetation classes in the thematic land cover data. The 2001 SEGAP has a $30 \mathrm{~m}$ x 30 
$\mathrm{m}$ resolution and was derived using the Landsat satellite image mosaics (leaf on, leaf off, and spring) made available through the Multi-Resolution Landscape Consortium (Homer et al. 2007). SEGAP used the National Land Cover Dataset, which is composed of 29 land cover classes, as a base layer to develop the more detailed 118 SEGAP land cover classes. The vegetation types in the SEGAP map are based on the Ecological Systems Classification (Comer et al. 2003). We summarized the percentage represented by each vegetation type within $400 \mathrm{~m}$ radius of each route segment for use as covariates in models. The average area covered by the buffered segments was 513 ha $(\mathrm{SE}=2 \mathrm{ha})$, which was defined by the length of each route segment by its radius $(400 \mathrm{~m})$. We used a $400 \mathrm{~m}$ radius, the detection radius prescribed by the BBS survey protocol, because in the absence of additional ancillary data, e.g., distance to detections, it was not possible to specify a nonarbitrary buffer applicable across the South Atlantic Coastal Plain. All data were processed in the North American Datum 1983 Albers, an equal area projection. All spatial analyses were performed with ArcMAP 9.2 and Arc Macro Language (ESRI Inc. 1999).

\section{Data analysis}

We used single-season, single-species occupancy models to estimate the probability of occupancy and detection (MacKenzie et al. 2002). Estimates were obtained via maximum likelihood using the program PRESENCE (Hines 2006). We converted counts per stop to presence (1) or nonpresence (0) data; species were considered present at a stop if at least one individual was detected. For example, an encounter history (h: 10100000) indicates that a bird was detected on the first and third count stop but not in any of the remaining six stops in the segment. BBS routes are unique in that the estimation of parameters is derived from spatial, not temporal replication along route segments or primary sampling units (Hines et al. 2010). The sequential placement and sampling of these stops increases the possibility that adjacent stops exhibit greater similarity of habitat than stops further apart. Indeed, we showed that our primary sampling units, the route segments, had fewer habitat classes as compared to the entire 50-stop route. Spatial correlation might also arise as a result of demographic patterns such as home ranges that encompass neighboring stops. These factors could lead to an increased probability of detection, or positive correlation between detection events. Failure to account for positive correlation between detection events yields estimates of occupancy that are biased-low. Hines et al. (2010) developed spatial dependence models to assess the possibility that the probability of occupancy is influenced by the state, occupied or not, of the previous survey stop or segment, i.e., 1st order spatial Markov process (Williams et al. 2002). We tested for this possibility by contrasting support in the data, i.e., lower
AIC, for a single season, single species model without spatial dependence (standard occupancy model parameterization) versus two variants of single season, single species models with spatial dependence also available in program PRESENCE. Our intent was not to discern the specific cause of spatial dependence in this work, but to account for it if the data supported the use of one of the spatial dependence model parameterizations. In such cases, we reported the adjusted estimates of occupancy.

We used the notation put forth by MacKenzie et al. (2002) and Hines et al. (2010) to describe the models in the candidate set. Parameters in the models were occupancy $(\psi)$ defined as the probability that a segment is occupied; detection $(p)$ defined as the probability of detection in a segment given that the segment is occupied and the species of interest present on the segment; theta $(\theta)$ defined as probability that a stop along the segment is occupied, given the segment is occupied and the previous stop is not occupied; and theta prime $\left(\theta^{\prime}\right)$ defined as the probability that a stop along the segment is occupied, given the segment is occupied and the previous stop is occupied. The candidate set of models included two types of model structures: the standard occupancy models $[\psi(),. p()$.$] and the$ spatial dependence model (Hines et al. 2010). We constrained both model structures by all habitat covariates (Doherty et al. 2012). We point out that the spatial dependence model has two variants, and we constrained with habitat covariates the variant with the lowest AIC. This determination was made after comparing variants to each other without covariates and with latitude (Franklin et al. 2004, Anthony et al. 2006). The two variants of the spatial dependence model are: (1) the generalized spatial dependence model structure $[\psi(),. \theta=\theta$, $p()$.$] ; and (2) the model structure with spatial dependence for$ all stops except the first one $[\psi(),. \theta \neq \theta$, $p()$.$] . The "dot"$ notation signifies constant or time-invariant. The former model structure (1) assumes that all stops are equally influenced by the state, occupied or not, of the preceding stop or surroundings (model notation is $\theta=\theta$; Hines et al. 2010). The alternative model structure (2) assumes that the occupancy of the first stop is not influenced by the state of the preceding surroundings, e.g., habitat, previous segment. Thus, the first stop and the rest of the stops in the segment are not equally subject to spatial dependence (model notation $\theta \neq \theta$; Hines et al. 2010). Model structure 1 was of particular interest because it provided a basis to account for the possible influence of preceding segments relative to the segment being assessed. We did not model detection probability within season or as a function of habitat surrounding individual stops. There were no criteria or ancillary information to partition the breeding season, e.g., singing rates, or to ascertain with accuracy the location of every survey stop to characterize their habitat. Only the first stop of every route is geo-referenced. Our review of yearly volunteer field notes confirmed that not all stops are equidistant $(0.8 \mathrm{~km})$ from the starting stop; observers make 
adjustments based on landscape and other considerations, e. g., road blocks or construction. We felt that the estimated stop location was sufficient to partition routes in segments, but not to pin-point a stop location accurately.

We included latitude as a covariate in all models because the SAMBI spans five states and nine degrees of latitude and it was possible that occupancy varied as a function of the location sampled within the species' range (Brown 1984, Lawton 1993) or distribution of plant communities across the region. For example, the Brown-headed Nuthatch is considered endemic to the southeast (Withgott and Smith 1998), but the SAMBI extends into the species' northern range boundary (Latitude $35-37^{\circ} \mathrm{N}$ ). As such it is expected that occurrence would be higher toward the southern and possibly closer to the center of the species' range as compared with its northern range. Route-specific latitudelongitude was not used because models were overparameterized. Thus, we stratified the SAMBI into three regions: southern $\left(\mathrm{LatS}=29\right.$ to $\left.31^{\circ} \mathrm{N}\right)$, central $(\mathrm{LatC}=32$ to $\left.34^{\circ} \mathrm{N}\right)$, and northern $\left(\mathrm{LatN}=35\right.$ to $\left.37^{\circ} \mathrm{N}\right)$. This categorical covariate yielded three sections of the SAMBI that were approximately of equal size (Iglecia 2010), contained roughly similar numbers of route segments (southern $=168$, central $=204$, northern $=108$ ), and preserved the overarching bioclimatic gradient for meaningful contrasts among its sections, e.g., northern vs. southern. In the case of woodpeckers, not all models could be parameterized with the three latitude covariates because of convergence problems. Thus, we contrasted three combinations, each consisting of a single region versus the other two, e.g., northern vs. central and southern regions, and then using the combination with highest support to further constrain with habitat covariates. We ranked models using Akaike's Information Criterion (AIC) and considered models with $\triangle \mathrm{AIC} \leq 2$ to have strong support (Burnham and Anderson 2002). Before running models, all continuous covariates were normalized. The relationship between the probability of occupancy and covariates at the segment level was established using a logistic model (logit link) in program PRESENCE (Hines 2006). We considered an effect, i.e., covariate beta coefficient, to be strongly supported if the $95 \%$ confidence intervals did not overlap zero. A Goodness of Fit (GOF) test was only available for the standard occupancy model (Mackenzie and Bailey 2004). We reported model GOF results for standard occupancy models that were among competing models $(\triangle \mathrm{AIC} \leq 2)$.

We evaluated the support in the data for the purported suitability ranks of vegetation types advanced by Hamel (1992). Hamel ranked southeastern vegetation types in decreasing order of suitability for terrestrial land birds using three categories: optimal, suitable, and marginal. Suitability rankings were created based on published studies, available information on natural history, survey data, expert opinion, and field experiences (Hamel et al. 1982, Hamel 1992). Optimal habitat was defined as vegetation types that supported the highest frequency or abundance of a species. Suitable and marginal habitats were defined as vegetation types that supported species in successively lower frequency or abundance. Accordingly, we expected support in the data for each species to be greater for optimal habitat, followed by suitable and marginal (i.e., $\mathrm{O}>\mathrm{S}>\mathrm{M}$; Table 1). To test hypothesized associations, we matched the definitions of each of the 118 SEGAP land cover classes (www.basic.ncsu.edu/ segap/datazip/region/lc segap legend.pdf; Iglecia 2010) with the vegetation types described by Hamel (1992). We pooled land cover classes to match the species-specific definitions of vegetation types considered optimal, suitable, and marginal habitat, and summarized their percentages within the BBS route-segments. For the Red-headed Woodpecker we created two models of optimal habitat. One followed Hamel's (1992) grouping of vegetation types considered optimal. The other (Optimal-revised) included grassland and shrub habitats, deemed important for the woodpeckers according to Venables and Collopy (1989), Kale and Maehr (1990) and Thogmartin and Knutson (2007).

\section{Model assumptions}

Careful consideration of model assumptions is important for interpreting results. Single-season occupancy models assume that: (1) the system was closed to changes in occupancy during the sampling period; (2) the species was not falsely detected; and (3) species detections were independent. The first two assumptions were likely met given that surveys were conducted in one morning by qualified bird observers, but there was always a chance that habitat similarity between adjacent stops or home ranges centered between stops might have violated the first assumption (Hines et al. 2010). We addressed the third assumption by testing for spatial dependence and reporting the appropriate (adjusted or not) occupancy estimates. We made this determination by contrasting models with and without spatial dependence as described in the data analysis section. We also assumed that both the grain, i.e., $30 \times 30 \mathrm{~m}$ pixels, and the thematic resolution (habitat classes) were reasonable for developing avian species-habitat models. We believe that the grain assumption was met because all species have territory sizes larger than 20 pixels. We assumed that the land cover was an adequate representation of the available habitat on the ground.

\section{RESULTS}

A regional average estimate of occupancy, i.e., not constrained by latitude or habitat, for the nuthatch was $0.46(\mathrm{SE}=0.14)$, $0.57(\mathrm{SE}=0.24)$ for the wood-pewee, and $0.41(\mathrm{SE}=0.09)$ for the woodpecker. Corresponding detection probabilities for the nuthatch were $0.38(\mathrm{SE}=0.20), 0.25(\mathrm{SE}=0.07)$ for the wood-pewee, and $0.06(\mathrm{SE}=0.01)$ for the woodpecker. There was evidence for variation in occupancy across the latitudinal 
Table 1. Vegetation types ranked by their suitability for three avian species in the South Atlantic Coastal Plain, United States, based on expert knowledge (Hamel 1992). Candidate model sets were evaluated with single-season occupancy models. The purported strength between occupancy probability and Hamel's habitat suitability categories was: optimal $(\mathrm{O})>$ suitable $(\mathrm{S})$ > marginal (M). Optimal habitat for the woodpecker was defined as per Hamel (1992) and as Optimal-revised to reflect recent literature on the species (see text).

\begin{tabular}{|c|c|c|c|}
\hline \multirow[t]{2}{*}{ Avian Species } & \multicolumn{3}{|c|}{ Vegetation Types } \\
\hline & Optimal (O) & Suitable (S) & Marginal (M) \\
\hline Brown-headed Nuthatch & $\begin{array}{c}\text { Sandhills longleaf pine } \\
\text { Longleaf pine-Slash pine } \\
\text { Loblolly pine-Shortleaf pine } \\
\text { Longleaf pine-scrub oak }\end{array}$ & $\begin{array}{c}\text { Pine savanna } \\
\text { Pond pine pocosin }\end{array}$ & Mixed pine-hardwood \\
\hline Red-headed Woopecker & $\begin{array}{l}\text { Sandhills longleaf pine } \\
\text { Longleaf-Slash pine } \\
\text { Grassland/Shrub }\end{array}$ & $\begin{array}{c}\text { Pine savanna } \\
\text { Pond pine pocosin } \\
\text { Longleaf pine-Scrub oak } \\
\text { Oak-gum-cypress } \\
\text { Oak-hickory }\end{array}$ & $\begin{array}{l}\text { Mixed pine-hardwood } \\
\text { Loblolly pine-Shortleaf pine } \\
\text { Bayswamp-pocosin } \\
\text { Elm-ash-cottonwood } \\
\text { Live oak maritime }\end{array}$ \\
\hline Eastern Wood-pewee & $\begin{array}{c}\text { Sandhills longleaf pine } \\
\text { Longleaf pine-Slash pine } \\
\text { Loblolly pine-Shortleaf pine } \\
\text { Mixed pine-hardwood } \\
\text { Oak-hickory } \\
\text { Southern mixed mesic hardwoods }\end{array}$ & $\begin{array}{c}\text { Longleaf pine-scrub oak } \\
\text { Bayswamp-pocosin } \\
\text { Elm-ash-cottonwood }\end{array}$ & $\begin{array}{l}\text { Pine savanna, } \\
\text { Pond pine pocosin } \\
\text { Oak-gum-cypress } \\
\text { Live oak maritime }\end{array}$ \\
\hline
\end{tabular}

gradient encompassed by the South Atlantic Migratory Bird Initiative region in the coastal plain (Beta $95 \% \mathrm{CI}$ did not overlap zero; Table 2). Occupancy was highest for the nuthatch in the central region of the SAMBI, in the southern and central region for the woodpecker, and in the northern region for the wood-pewee (Fig. 2).

Models that included optimal habitat were strongly supported for the nuthatch and wood-pewee (Tables 3 and 4). These models also featured adjustments for spatial dependence among survey stops. For both species, optimal habitat accounted for most of the variation in occupancy probability. Occupancy was positively and strongly influenced by optimal habitat (Nuthatch: Beta $=0.34 \pm 0.09$, 95\%CIs: $0.16-0.50$; pewee: Beta $=0.33 \pm 0.08,95 \%$ CIs: $0.17-0.49$; Table 2). In the case of the woodpecker, a model structure that did not include within-route spatial dependence received greater support (Table 5). Marginal habitat was at the top of ranked models but its weight was low (0.31, Table 5). In this model, occupancy was positively but weakly influenced by marginal habitat $($ Beta $=0.45$ \pm 0.30 ; 95\%CIs: $-0.15-1.05)$. Two other models were plausible alternatives $(\triangle \mathrm{AIC} \leq 2)$; a model that did not include habitat covariates and a model that included the Optimal-revised habitat.

\section{DISCUSSION}

The use of expert knowledge for landscape level conservation is widespread, and in recent years, the application of expert knowledge for such aims has benefited from advances on how knowledge is elicited, verified, and quantified for modeling (Low-Choy et al. 2009, McBride and Burgman 2012). However, expert-based models and purported species-habitat relationships continue to suffer from inadequate validation (Doswald et al. 2007, Schlossberg and King 2009, Johnson et al. 2012). Our aim in this work was to extend and illustrate the landscape scale application of occupancy models to validate such models. We assessed the support for expert knowledge-based avian species-habitat associations in the context of detailed thematic land cover dataset for the South Atlantic Coastal Plain of the United States. Models supported two of the three purported specieshabitat suitability associations. The nuthatch and wood-pewee were positively and strongly associated with optimal habitat as proposed by Hamel (1992). Vegetation types considered to be optimal habitat for the woodpecker received low support from the data $(\triangle \mathrm{AIC}>2)$. Indeed, all of the habitat variables included in the models had low influence on woodpecker occupancy, which was contrary to expert opinion. The low support for the expected woodpecker-optimal habitat relationship may be a sampling artifact, reflecting the locations within the species range visited by observers. Alternatively, the absence of a strong relationship between woodpecker occupancy and optimal habitat may indicate that Hamel (1992) may have overstated the importance of some vegetation types for this species. The value of habitat deemed optimal may have also been overrepresented by drawing inferences from surveys 
Table 2. Beta coefficients and standard errors $(\beta \pm$ SE) for occupancy $(\psi)$ estimates derived from models with highest support $(\triangle \mathrm{AIC})$ in the data using single season occupancy models for three avian species of conservation priority in the South Atlantic Coastal Plain, United States, 2001. Covariates were latitude: $\left(\mathrm{LatS}=29-31^{\circ}, \mathrm{LatC}=32-34^{\circ} \mathrm{N}, \mathrm{LatN}=35-37^{\circ} \mathrm{N}\right)$ and Hamel's habitat suitability categories, namely, optimal $(\mathrm{O})$, suitable $(\mathrm{S})$, and marginal $(\mathrm{M})$.

\begin{tabular}{|c|c|c|c|c|c|c|}
\hline \multirow[b]{2}{*}{ Covariate } & \multicolumn{2}{|c|}{$\begin{array}{l}\text { Brown-headed nuthatch } \\
\text { (Sitta pusilla) }\end{array}$} & \multicolumn{2}{|c|}{$\begin{array}{c}\text { Red-headed woodpecker } \\
\text { (Melanerpes erythrocephalus) }\end{array}$} & \multicolumn{2}{|c|}{$\begin{array}{l}\text { Eastern wood-pewee } \\
\text { (Contopus virens) }\end{array}$} \\
\hline & $\beta$ & $\mathrm{SE}$ & $\beta$ & SE & $\beta$ & SE \\
\hline$\overline{\text { LatS }}$ & -0.18 & 0.26 & - & - & $-1.82^{\dagger}$ & 0.29 \\
\hline LatC & $0.54^{\dagger}$ & 0.22 & - & - & -0.82 & 0.22 \\
\hline LatN & - & - & $-1.87^{\dagger}$ & 0.68 & - & - \\
\hline $\mathrm{O}$ & $0.33^{\dagger}$ & 0.08 & - & - & $0.34^{\dagger}$ & 0.09 \\
\hline S & - & - & - & - & - & - \\
\hline $\mathrm{M}$ & - & - & 0.45 & 0.30 & - & - \\
\hline
\end{tabular}

$\dagger 95 \%$ confidence intervals do not overlap zero

Table 3. Model selection results for Brown-headed Nuthatch (Sitta pusilla) occupancy models in the South Atlantic Coastal Plain, United States, 2001. Occupancy $(\psi)$ was modeled as constant (.), as a function of latitude ( $\mathrm{LatS}=29-31^{\circ}, \mathrm{LatC}=32-34^{\circ} \mathrm{N}, \mathrm{LatN}$ $\left.=35-37^{\circ} \mathrm{N}\right)$ and Hamel's habitat suitability categories, namely, optimal $(\mathrm{O})$, suitable $(\mathrm{S})$, and marginal $(\mathrm{M})$. Detection probability $(p)$ was modeled as constant (.). Models account for spatial correlation within segment stations $\left(\theta=\theta^{`}\right.$ or $\left.\theta \neq \theta^{\prime}\right)$. The term Basic Model means that occupancy $(\psi)$ was not constrained by a covariate, or constrained by latitude. S-D means spatial dependence model structure; Std-O means standard occupancy model structure. LatN defaults to the intercept in the model parameterization. $\mathrm{N}=480$ route segments.

\begin{tabular}{|c|c|c|c|c|c|}
\hline Model Set & Model & $\mathrm{K}^{\dagger}$ & $\Delta \mathrm{AIC}^{\ddagger}$ & $\mathrm{w}^{\S}$ & Deviance \\
\hline Hamel S-D & $\psi($ Optimal + LatS + LatC $),\left(\theta \neq \theta^{\prime}\right), p(.)^{\mid}$ & 7 & 0 & 0.986 & 829.50 \\
\hline Hamel Std-O & $\psi($ Optimal + LatS + LatC $), p()$. & 5 & 8.66 & 0.013 & 842.16 \\
\hline Hamel S-D & $\psi($ Marginal + LatS + LatC $),\left(\theta \neq \theta^{\prime}\right), p()$. & 7 & 17.90 & 0.0001 & 847.40 \\
\hline Hamel S-D & $\psi($ Suitable + LatS + LatC $),\left(\theta \neq \theta^{\prime}\right), p()$. & 7 & 18.20 & 0.0001 & 847.70 \\
\hline Basic S-D & $\psi($ LatS + LatC $),\left(\theta \neq \theta^{\prime}\right), p()$. & 6 & 18.87 & 0.0001 & 850.37 \\
\hline Hamel Std-O & $\psi($ Suitable + LatS + LatC $), p()$. & 5 & 26.48 & 0 & 859.98 \\
\hline Hamel Std-O & $\psi($ Marginal + LatS + LatC), $p()$. & 5 & 26.58 & 0 & 860.08 \\
\hline Basic Std-O & $\psi($ LatS + LatC $), p()$. & 4 & 26.81 & 0 & 862.31 \\
\hline Basic Std-O & $\psi(),.\left(\theta \neq \theta^{\prime}\right), p()$. & 4 & 41.97 & 0 & 877.47 \\
\hline Basic Std-O & $\psi(),.\left(\theta=\theta^{\prime}\right), p()$. & 4 & 42.71 & 0 & 878.21 \\
\hline Basic Std-O & $\psi(),. p()$. & 2 & 47.46 & 0 & 886.96 \\
\hline
\end{tabular}

Number of parameters

Difference between the AIC of a given model and the lowest AIC in the set of candidate models.

$\S$ AIC weights indicate the likelihood that a given model is the best model in the set of competing models given the data.

${ }^{\prime}$ Hamel Model AIC $=843.50$ 
Table 4. Model selection results for Eastern Wood-Pewee (Contopus virens) occupancy models in the South Atlantic Coastal Plain, United States, 2001. Occupancy $(\psi)$ was modeled as constant (.), as a function of latitude (Lat S $=29-31^{\circ}, \mathrm{LatC}=32-34^{\circ} \mathrm{N}, \mathrm{LatN}=35-37^{\circ} \mathrm{N}$ ) and $\mathrm{Hamel}$ 's habitat suitability categories, namely, optimal $(\mathrm{O})$, suitable $(\mathrm{S})$, and marginal $(\mathrm{M})$. Detection probability $(p)$ was modeled as constant (.). Models account for spatial correlation within segment stations $\left(\theta=\theta^{\prime}\right.$ or $\left.\theta \neq \theta^{\prime}\right)$. The term Basic Model means that occupancy ( $\left.\psi\right)$ was not constrained by a covariate, or constrained by latitude. S-D means spatial dependence model structure; Std-O means standard occupancy model structure. LatN defaults to the intercept in the model parameterization. $\mathrm{N}=480$ route segments.

\begin{tabular}{|c|c|c|c|c|c|}
\hline Model Set & Model & $\mathrm{K}^{\dagger}$ & $\Delta \mathrm{AIC}^{\ddagger}$ & $w^{\S}$ & Deviance \\
\hline Hamel S-D & $\psi($ Optimal + LatS + LatC $),\left(\theta \neq \theta^{\prime}\right), p(.)^{l}$ & 7 & 0 & 0.81 & 1505.96 \\
\hline Hamel Std-O & $\psi($ Optimal + LatS + LatC), $p()$. & 5 & 2.9 & 0.18 & 1512.86 \\
\hline Basic S-D & $\psi($ LatS + LatC $),\left(\theta \neq \theta^{\prime}\right), p()$. & 6 & 15.76 & 0.0003 & 1523.72 \\
\hline Hamel S-D & $\psi($ Suitable + LatS + LatC $),\left(\theta \neq \theta^{\prime}\right), p()$. & 7 & 17 & 0.0002 & 1522.96 \\
\hline Hamel S-D & $\psi($ Marginal + LatS + LatC $),\left(\theta \neq \theta^{\prime}\right), p()$. & 7 & 17.6 & 0.0001 & 1523.56 \\
\hline Basic Std-O & $\psi($ LatS + LatC $), p()$. & 4 & 20.44 & 0 & 1532.40 \\
\hline Hamel Std-O & $\psi(\mathrm{LatS}+\mathrm{LatC}+\mathrm{M}), p()$. & 5 & 21.96 & 0 & 1531.92 \\
\hline Hamel Std-O & $\psi(\mathrm{LatS}+\mathrm{LatC}+\mathrm{S}), p()$. & 5 & 22.26 & 0 & 1532.22 \\
\hline Basic S-D & $\psi(),.\left(\theta \neq \theta^{\prime}\right), p()$. & 4 & 86.97 & 0 & 1598.93 \\
\hline Basic Std-O & $\psi(),. p()$. & 2 & 88.2 & 0 & 1604.16 \\
\hline Basic S-D & $\psi(),.\left(\theta=\theta^{\prime}\right), p()$. & 4 & 88.64 & 0 & 1600.60 \\
\hline
\end{tabular}

Number of parameters

Difference between the AIC of a given model and the lowest AIC in the set of candidate models.

$\$$ AIC weights indicate the likelihood that a given model is the best model in the set of competing models given the data.

' Hamel-NLCD Model AIC $=1519.96$

Table 5. Model selection results for Red-headed Woodpecker (Melanerpes erythrocephalus) occupancy models in the South Atlantic Coastal Plain, United States, 2001. Occupancy $(\psi)$ was modeled as constant $($.$) , as a function of latitude \left(\mathrm{LatS}=29-31^{\circ}, \mathrm{LatC}=32-34^{\circ} \mathrm{N}, \mathrm{LatN}=35-37^{\circ}\right.$ $\mathrm{N}$ ) and Hamel's habitat suitability categories, namely, optimal $(\mathrm{O})$, suitable (S), and marginal (M). Optimal habitat was modeled as defined by Hamel (1992) and as Optimal-revised to reflect recent literature on the species (see text). Detection probability $(p)$ was modeled as constant (.). Models account for spatial correlation within segment stations $\left(\theta=\theta^{\circ}\right.$ or $\left.\theta \neq \theta^{\prime}\right)$. The term Basic Model means that occupancy $(\psi)$ was not constrained by a covariate, or constrained by latitude. S-D means spatial dependence model structure; Std-O means standard occupancy model structure. LatN defaults to the intercept in model parameterizations when modeled with LatS and LatC. In the final model parameterization, which featured one latitude category at a time, LatS and LatC default to the intercept. Model assumptions for the standard occupancy model were met $(\mathrm{GOF} \chi 2=142.70, \mathrm{P}=0.18) . \mathrm{N}=480$ route segments.

\begin{tabular}{|c|c|c|c|c|c|}
\hline Model Set & Model & $\mathrm{K}^{\dagger}$ & $\Delta \mathrm{AIC}^{\ddagger}$ & $w^{\S}$ & Deviance \\
\hline Hamel Std-O & $\psi($ Marginal + LatN $), p(.)^{\mid}$ & 4 & 0 & 0.31 & 647.24 \\
\hline Basic Std-O & $\psi(\operatorname{LatN}), p()$. & 3 & 1.55 & 0.15 & 650.79 \\
\hline Hamel Std-O & $\psi($ Optimal + LatN), $p()$. & 4 & 1.96 & 0.13 & 649.2 \\
\hline Basic Std-O & $\psi($ LatS + LatC $), p()$. & 4 & 2.44 & 0.10 & 649.68 \\
\hline Hamel Std-O & $\psi($ Optimal-Hamel + LatN), $p()$. & 4 & 3.13 & 0.07 & 650.37 \\
\hline Hamel Std-O & $\psi($ Suitable + LatN $), p()$. & 4 & 3.3 & 0.06 & 650.54 \\
\hline Hamel S-D & $\psi($ Marginal + LatN $),\left(\theta=\theta^{\prime}\right), p()$. & 6 & 3.43 & 0.05 & 646.67 \\
\hline Hamel S-D & $\psi($ Marginal + LatS + LatC $),\left(\theta=\theta^{\prime}\right), p()$. & 7 & 3.57 & 0.05 & 644.81 \\
\hline Hamel S-D & $\psi($ Optimal + LatS + LatC $),\left(\theta=\theta^{\prime}\right), p()$. & 7 & 4.59 & 0.03 & 645.83 \\
\hline Hamel S-D & $\psi($ Suitable + LatS + LatC $),\left(\theta=\theta^{\prime}\right), p()$. & 7 & 5.33 & 0.02 & 646.57 \\
\hline Hamel S-D & $\psi($ Optimal-Hamel + LatS + LatC $),\left(\theta=\theta^{\prime}\right), p()$. & 7 & 5.76 & 0.02 & 647 \\
\hline Basic Std-O & $\psi(\mathrm{LatC}), p()$. & 3 & 5.97 & 0.01 & 655.21 \\
\hline Basic Std-O & $\psi(),. p()$. & 2 & 9.82 & 0.00 & 661.06 \\
\hline Basic Std-O & $\psi($ LatS $), p()$. & 3 & 11.81 & 0.00 & 661.05 \\
\hline Basic S-D & $\psi(),.\left(\theta=\theta^{\prime}\right), p()$. & 4 & 12.5 & 0.00 & 659.74 \\
\hline Basic S-D & $\psi(),.\left(\theta \neq \theta^{\prime}\right), p()$. & 4 & 13.75 & 0.00 & 660.99 \\
\hline
\end{tabular}

Number of parameters

Difference between the AIC of a given model and the lowest AIC in the set of candidate models.

$\S$ AIC weights indicate the likelihood that a given model is the best model in the set of competing models given the data.

${ }^{\prime}$ Hamel Model AIC= 655.24 
Fig. 2. Location of route segments with high probabilities of occupancy $(0.7-0.9)$ for the Brown-headed Nuthatch (Sitta pusilla), Eastern Wood-pewee (Contopus virens), and Red-headed Woodpecker (Melanerpes erythrocephalus) in the South Atlantic Coastal Plain, United States, 2001. Occupancy was modeled as a function of the amount of optimal habitat (marginal for the woodpecker; Hamel 1992) and latitude. Latitude was a categorical covariate $\left(\mathrm{LatS}=29-31^{\circ}, \mathrm{LatC}=32-34^{\circ} \mathrm{N}\right.$, LatN $\left.=35-37^{\circ} \mathrm{N}\right) ; 400 \mathrm{~m}$ is the width of survey routes. Models account for probability of species detection and spatial correlation within segments stations.

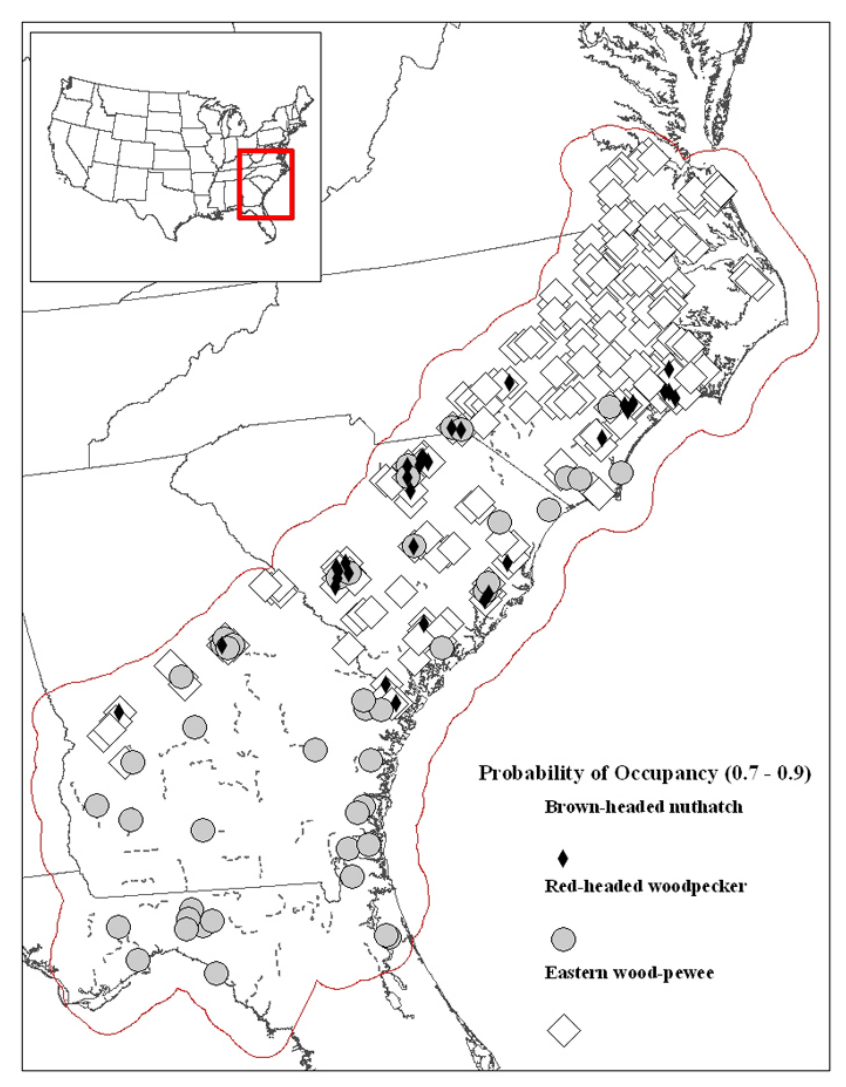

without adjusting for detection probability (Mackenzie et al. 2002, Mackenzie 2006).

The lack of strong predictive habitat covariates in our woodpecker models was consistent with previous studies of other habitat generalists in that they failed to identify strong habitat predictors of abundance or occurrence (Dettmers et al. 2002, Manel et al. 2001, Kadmon et al. 2003, Thogmartin and Knutson 2007). The woodpecker illustrates the possibility that for some species models with land cover data and latitude alone might not adequately predict occupancy (Lawler et al. 2004). The 2001 SEGAP database consisted of 118 land cover classes as compared to NLCD's 29 classes (Wickham et al. 2010). For generalist species like the redheaded woodpecker, experts may have difficulty attributing habitat suitability rankings, and further parsing land cover into finer classes might not improve estimates of species occurrence. In these cases, other habitat requirements might be necessary to improve estimates of occurrence. For woodpeckers, site covariates might include the presence of masting tree species or sampling covariates such as masting year.

Occupancy models, as those described here, provide a welldeveloped analytical framework to validate expert knowledgebased models (McKenzie et al. 2006). The benefit to conservation planning is heightened because datasets such as BBS and regional land cover data like SEGAP can be used to conduct such tests at landscape levels. We suggest that validation tests might be improved if the width of buffers around BBS routes explicitly reflects the functional relationship between detections and distance from survey stops (e.g., Somershoe et al. 2006). The need is underscored by increasing trends in ambient noise along routes that may make detection with increasing distance from the survey stops more difficult (Simons et al. 2007, 2009). Finally, available NLCD data from 1992 and 2006 provide base layers to create land cover datasets like the 2001 SEGAP. The prospect of creating multiyear land cover datasets raises the possibility of assessing the robustness or model inference consistency with respect to expert knowledge-based species-habitat relationships. Insights about underlying processes, e.g., patch extinction and colonization rates, that might explain the outcomes of such assessments could be gained by accounting for landscape scale features such as patch size, amount of habitat, and distance among patches using multiseason occupancy frameworks (Mordecai et al. 2011, Veran et al. 2012).

Responses to this article can be read online at: http://www.ace-eco.org/issues/responses.php/551

\section{Acknowledgments:}

We thank the Biodiversity and Spatial Information Center at North Carolina State University and the Patuxent Wildlife Research Center for their logistical and analytical support. We thank the Association of Fish and Wildlife Agencies for funding this research. We are grateful to S. Williams for assistance with coding and spatial analyses, and to J. Nichols, J. Hines, M. Krachey, G. Brown, and K. Pollock for their statistical advice. We also thank A. Drew, N. Haddad, R. Mordecai, and three anonymous reviewers for helpful comments on earlier drafts of this manuscript. Any use of trade, product, or firms names is for descriptive purposes only and does not imply endorsement by the U.S. government. 


\section{LITERATURE CITED}

Allen, C. R., J. J. Fontaine, K. L. Pope, and A. S. Garmestani. 2011. Adaptive management for a turbulent future. Journal of Environmental Management 92:1339-1345.

Anthony, R. G., E. D. Forsman, A. B. Franklin, D. R. Anderson, K. P. Burnham, G. C. White, C. J. Schwarz, J. D. Nichols, J. E. Hines, G. S. Olson, S. H. Ackers, L. S. Andrews, B. L. Biswell, P. C. Carlson, L. V. Diller, K. M. Dugger, K. E. Fehring, T. L. Fleming, R. P. Gerhardt, S. A. Gremel, R. J. Gutierrez, P. J. Happe, D. R. Herter, J. M. Higley, R. B. Horn, L. L. Irwin, P. J. Loschl, J. A. Reid, and S. G. Sovern. 2006. Status and trends in demography of Northern Spotted Owls, 1985-2003. Wildlife Monographs 163:1-48. http://dx.doi.org/10.2193/0084-0173(2006)163 [1:SATIDO]2.0.CO;2

Bailey, D., F. Herzog, I. Augenstein, S. Aviron, R. Billeter, E. Szerencsits, and J. Baudry. 2007. Thematic resolution matters: indicators of landscape patter for European agroecosystems. Ecological Indicators 7:692-709. http://dx.doi. org/10.1016/j.ecolind.2006.08.001

Brown, J. H. 1984. On the relationship between abundance and distribution of species. American Naturalist 124:255-279. http://dx.doi.org/10.1086/284267

Burgman, M. A. 2005. Risks and decisions for conservation and environmental management. Cambridge University Press, Cambridge, UK. http://dx.doi.org/10.1017/

$\underline{\mathrm{CBO} 9780511614279}$

Burnham, K. P., and D. R. Anderson. 2002. Model selection and multimodel inference. Second Edition. Springer, New York, New York, USA. http://dx.doi.org/10.1007/b97636

Clevenger, A. P., J. Wierzchowski, B. Chruszcz, and K. Gunson. 2002. GIS-generated, expert-based models for identifying wildlife habitat linkages and planning mitigation passages. Conservation Biology 16:503-514. http://dx.doi. org/10.1046/j.1523-1739.2002.00328.x

Comer, P., D. Faber-Langendoen, R. Evans, S. Gawler, C. Josse, G. Kittel, S. Menard, M. Pyne, M. Reid, K. Schulz, K. Snow, and J. Teague. 2003. Ecological systems of the United States: a working classification of U.S. terrestrial systems. NatureServe, Arlington, Virginia, USA.

Dettmers, R., D. A. Buehler, and K. E. Franzreb. 2002. Testing habitat-relationship models for forest birds of the Southeastern United States. Journal of Wildlife Management 66:417-424. http://dx.doi.org/10.2307/3803174

Doherty, P. F., G. C. White, and K. P. Burnham. 2012. Comparison of model building and selection strategies. Journal of Ornithology 152(Suppl 2):S317-S323. http://dx. doi.org/10.1007/s10336-010-0598-5
Doswald, N., F. Zimmerman, and U. Breitenmoser. 2007. Testing expert groups for a habitat suitability model for the lynx Lynx lynx in the Swiss Alps. Wildlife Biology 13:430-446. http://dx.doi.org/10.2981/0909-6396(2007)13[430:TEGFAH] 2.0.CO;2

Drew, C. A., and J. A. Collazo. 2012. Expert knowledge as a foundation for the management of secretive species and their habitat. Chapter 5 in A. H. Perera, C. A. Drew, and C. J. Johnson, editors. Expert knowledge and its application in landscape ecology. Springer, New York, New York, USA. http://dx.doi.org/10.1007/978-1-4614-1034-8 5

Drew, C. A., and A. H. Perera. 2011. Expert knowledge as a basis for landscape ecological predictive models. Chapter 12 in C. A. Drew, Y. F. Wiersma, and F. Huettmann, editors. Predictive species and habitat modeling in landscape ecology: concepts and applications Springer, New York, New York, USA. http://dx.doi.org/10.1007/978-1-4419-7390-0 12

Flather, C. H., and J. R. Sauer. 1996. Using landscape ecology to test hypotheses about large-scale abundance patterns in migratory birds. Ecology 77:28-35. http://dx.doi.org/10.2307/2265651

Forbush, E. H. 1927. Birds of Massachusetts and other New England states. Massachusetts Department of Agriculture, Norwood Press, Norwood, Massachusetts, USA. http://dx.doi. org/10.5962/bhl.title.49838

Franklin, A. B., R. J. Gutierrez, J. D. Nichols, M. E. Seamans, G. C. White, G. S. Zimmerman, J. E. Hines, T. E. Munton, W. S. LaHaye, J. A. Blakesley, G. N. Steger, B. R. Noon, D. W. H. Shaw, J. J. Keane, T. L. McDonald, and S. Britting. 2004. Population dynamics of the California Spotted Owl (Strix occidentalis occidentalis): a meta-analysis. Ornithological Monographs 54:1-54. http://dx.doi.org/10.2307/40166799

Hamel, P. B. 1992. The land manager's guide to the birds of the south. The Nature Conservancy, Southeastern Region, Chapel Hill, North Carolina, USA.

Hamel, P. B., H. E. LeGrand, Jr., M. R. Lennartz, and S. A. Gauthreaux, Jr. 1982. Bird habitat relationships on southeastern forest lands. General Technical Report SE-22, U.S. Forest Service, Washington, D.C., USA.

Hines, J. E. 2006. PRESENCE 5.3. Software to estimate patch and occupancy rates and related parameters. USGS-Patuxent Wildlife Research Center, Laurel, Maryland, USA. http:// www.mbr-pwrc.usgs.gov/software/presence.html

Hines, J. E., J. D. Nichols, J. A. Royle, D. I. Mackenzie, A. M. Gopalaswamy, N. S. Kumar, and K. U. Karanth. 2010. Tigers on trails: occupancy modeling for cluster sampling. Ecological Applications 20:1456-1466. http://dx.doi. org/10.1890/09-0321.1

Homer, C., J. Dewitz, J. Fry, M. Coan, N. Hossain, C. Larson, N. Herold, A. McKerrow, J. N. VanDriel, and J. Wickham. 
2007. Completion of the 2001 National Land Cover Database for the conterminous United States. Photogrammetric Engineering and Remote Sensing 73:337-341.

Hunter, W. C., L. Peoples, and J. A. Collazo. 2001. South Atlantic Coastal Plain Partners In Flight bird conservation plan (Physiographic area 03). Partners In Flight, Raleigh, North Carolina, USA.

Hupp, C. R. 2000. Hydrology, geomorphology and vegetation of coastal plain rivers in the southeastern USA. Hydrological Processes 14:2991-3010. http://dx.doi. org/10.1002/1099-1085(200011/12)14:16/17<2991::AIDHYP131>3.0.CO;2-H

Iglecia, M. N. 2010. Occupancy modeling and strategic habitat conservation for avian species in the southeastern coastal plain of the United States. Thesis. North Carolina State University, Raleigh, North Carolina, USA.

Johnson, C. J., and M. P. Gillingham. 2004. Mapping uncertainty: sensitivity of wildlife habitat ratings to expert opinion. Journal of Applied Ecology 41:1032-1041. http:// dx.doi.org/10.1111/j.0021-8901.2004.00975.x

Johnson, C. J., M. Hurley, E. Rapaport, and M. Pullinger. 2012. Using expert knowledge effectively: lessons from species distribution models for wildlife conservation and management. Chapter 8 in A. H. Perera, C. A. Drew, and C. J. Johnson, editors. Expert knowledge and its application in landscape ecology. Springer, New York, New York, USA. http://dx.doi.org/10.1007/978-1-4614-1034-8 8

Kadmon, R., O. Farber, and A. Danin. 2003. A systematic analysis of factors affecting the performance of climatic envelope models. Ecological Applications 13:853-867. http://dx.doi.org/10.1890/1051-0761(2003)013[0853:ASAOFA] 2.0.CO;2

Kale, H. W., and D. S. Maehr. 1990. Florida's birds: a handbook and reference. Pineapple Press, Sarasota, Florida, USA.

Kaufman, K. 1996. Lives of North American birds. Houghton Mifflin, Boston, Massachusetts, USA.

Lawler, J. J., R. J. O’Connor, C. T. Hunsaker, K. B. Jones, T. R. Loveland, and D. White. 2004. The effects of habitat resolution on models of avian diversity and distributions: a comparison of two land-cover classifications. Landscape Ecology 19:515-530. http://dx.doi.org/10.1023/B: LAND.0000036151.28327.01

Lawton, J. H. 1993. Range, population abundance and conservation. Trends in Ecology \& Evolution 8:409-413. http://dx.doi.org/10.1016/0169-5347(93)90043-O

Low-Choy, S., R. O'Leary, and K. Mengersen. 2009. Elicitation by design for ecology: using expert opinion to inform priors for Bayesian statistical models. Ecology 90:265-277. http://dx.doi.org/10.1890/07-1886.1

MacKenzie, D. I. 2006. Modeling the probability of resource use: the effect of, and dealing with, detecting a species imperfectly. Journal of Wildlife Management 70:367-374. http://dx.doi.org/10.2193/0022-541X(2006)70[367:MTPORU] 2.0.CO;2

MacKenzie, D. I., and L. L. Bailey. 2004. Assessing the fit of site occupancy models. Journal of Agricultural, Biological, and Environmental Statistics 9:300-318. http://dx.doi. org/10.1198/108571104X3361

MacKenzie, D. I., J. D. Nichols, G. B. Lachman, S. Droege, J. A. Royle, and C. A. Langtimm. 2002. Estimating site occupancy rates when detection probabilities are less than one. Ecology 83:2248-2255. http://dx.doi.org/10.1890/0012-9658 (2002)083[2248:ESORWD]2.0.CO:2

MacKenzie, D. I., J. D. Nichols, J. A. Royle, K. H. Pollock, L. L. Bailey, and J. E. Hines. 2006. Occupancy estimation and modeling: inferring patterns and dynamics of species occurrence. Academic Press: Elsevier, London, UK.

Manel, S., H. C. Williams, and S. J. Ormerod. 2001. Evaluating presence-absence models in ecology: the need to account for prevalence. Journal of Applied Ecology 38:921-931. http://dx. doi.org/10.1046/j.1365-2664.2001.00647.x

McBride, M. F., and M. A. Burgman. 2012. What is expert knowledge, how is such knowledge gathered, and how do we use it to address questions in landscape ecology? Chapter 2 in A. H. Perera, C. A. Drew, and C. J. Johnson, editors. Expert knowledge and its application in landscape ecology. Springer, New York, New York, USA. http://dx.doi.org/10.1007/978-1-4614-1034-8_2

McCarty, J. P. 1996. Eastern Wood-Pewee (Contopus virens). In A. Poole, editor. The birds of North America online. Cornell Lab of Ornithology, Ithaca, New York, USA. [online] URL: http://bna.birds.cornell.edu/bna/species/245/articles/introduction

McNair, D. B. 1984. Clutch-size and nest placement in the brown-headed nuthatch. Wilson Bulletin 96:296-301.

Meyers, J. M., and A. S. Johnson. 1978. Bird communities associated with succession and management of loblollyshortleaf pine forests. Pages 50-65 in R. M. DeGraaf, technical coordinator. Proceedings of the Workshop: Management of Southern Forests for Nongame Birds. General Technical Report SE-14, U.S. Forest Service, Washington, D. C., USA.

Mordecai, R. S., B. J. Mattsson, C. J. Tzilkowski, and R. J. Cooper. 2011. Addressing challenges when studying mobile or episodic species: hierarchical Bayes estimation of occupancy and use. Journal of Applied Ecology 48:56-66. http://dx.doi.org/10.1111/j.1365-2664.2010.01921.x 
North Carolina Wildlife Resources Commission (NCWRC). 2005. North Carolina wildlife action plan. NCWRC, Raleigh, North Carolina, USA.

Omernik, J. M. 1987. Ecoregions of the conterminous United States. Annals of the Association of American Geographers 77:118-125. http://dx.doi.org/10.1111/j.1467-8306.1987. tb00149.x

Perera, A. H., C. A. Drew, and C. J. Johnson. 2012. Experts, expert knowledge, and their roles in landscape ecological applications. Chapter 1 in A. H. Perera, C. A. Drew, and C. J. Johnson, editors. Expert knowledge and its application in landscape ecology. Springer, New York, New York, USA. http://dx.doi.org/10.1007/978-1-4614-1034-8 1

Potter, E. F., J. F. Parnell, and R. P. Teulings. 1980. Birds of the Carolinas. The University of North Carolina Press, Chapel Hill, North Carolina, USA.

Ricketts, T. H., E. Dinerstein, D. M. Olson, and C. J. Loucks. 1999. Terrestrial ecoregions of North America: a conservation assessment. Island Press, Washington, D.C., USA.

Robbins, C. S., D. K. Dawson, and B. A. Dowell. 1989. Habitat area requirements of breeding forest birds of the Middle Atlantic States. Wildlife Monographs 103:1-34.

Simons, T. R., M. W. Alldredge, K. H. Pollock, and J. M. Wettroth. 2007. Experimental analysis of the auditory detection process on avian point counts. Auk 124:986-999. http://dx.doi.org/10.1642/0004-8038(2007)124[986:EAOTAD] 2.0.CO;2

Simons, T. R., K. H. Pollock, J. M. Wettroth, M. W. Alldredge, K. Pacifici, and J. Brewster. 2009. Sources of measurement error, misclassification error, and bias in auditory avian point count data. Pages 237-254 in D. L. Thompson, E. G. Cooch, and M. J. Conroy, editors. Modeling demographic processes in marked populations. Environmental and Ecological Statistics Series Volume 3. Springer, New York, New York, USA. http://dx.doi. org/10.1007/978-0-387-78151-8_10

Schlossberg, S., and D. I. King. 2009. Modeling animal habitats based on cover types: a critical review. Environmental Management 43:609-618. http://dx.doi. org/10.1007/s00267-008-9159-6

Smith, P. W., and S. A. Smith. 1994. A preliminary assessment of the Brown-headed Nuthatch in the Bahamas. Bahamas Journal of Science 1:22-26.

Smith, K. G., J. H. Withgott, and P. G. Rodewald. 2000. Red-headed Woodpecker (Melanerpes erythrocephalus). In A. Poole, editor. The birds of North America online. Cornell Lab of Ornithology, Ithaca, New York, USA. [online] URL: http://bna.birds.cornell.edu/bna/species/518/articles/introduction
Somershoe, S. G., J. Twedt, and B. Reid. 2006. Combining breeding bird survey and distance sampling to estimate density of migrant and breeding birds. Condor 108:691-699 http://dx. doi.org/10.1650/0010-5422(2006)108[691:CBBSAD]2.0.CO;2

Sutherland, G. D., A. S. Harestand, K. Price, and K. P. Lertzman. 2000. Scaling of natal dispersal distances in terrestrial birds and mammals. Conservation Ecology 4:44.

Thogmartin, W. E., and M. G. Knutson. 2007. Scaling local species-habitat relations to the larger landscape with a hierarchical spatial count model. Landscape Ecology 22:61-75. http://dx.doi.org/10.1007/s10980-006-9005-2

U.S. Fish and Wildlife Service. 2008. Strategic habitat conservation handbook: a guide to implementing the technical elements of strategic habitat conservation (version 1.0). National Technical Assistance Team, U.S. Fish and Wildlife Service, Washington, D.C., USA.

Valiela, I., and P. Martinetto. 2007. Changes in bird abundance in eastern North America: urban sprawl and global footprint? BioScience 57:360-370. http://dx.doi.org/10.1641/B570410

Venables, A., and M. W. Collopy. 1989. Seasonal foraging and habitat requirements of Red-headed Woodpeckers in north-central Florida. Nongame Wildlife Program Final Report. Project number GFC-84-006. Florida Game Fresh Water Fish Commission, Tallahassee, Florida, USA.

Veran, S., K. J. Kleiner, R. Choquet, J. A. Collazo, and J. D. Nichols. 2012. Modeling habitat dynamics accounting for possible misclassification. Landscape Ecology 27:943-956. http://dx.doi.org/10.1007/s10980-012-9746-Z

Watson, C., and K. Malloy. 2006. The South Atlantic Migratory Bird Initiative implementation plan: an integrated approach to conservation of "all birds across all habitats". Atlantic Coast Joint Venture Report, Charleston, South Carolina, USA.

Watson, C., and K. McWilliams. 2005. The South Atlantic Migratory Bird Initiative - An integrated approach to conservation of "All Birds Across All Habitats". General Technical Report, U.S. Forest Service, Washington, D.C., USA.

Wickham, J. D., S. V. Stehman, J. A. Fry, J. H. Smith, and C. G. Homer. 2010. Thematic accuracy of the NLCD 2001 land cover for the conterminous United States. Remote Sensing of Environment 114:1286-1296. http://dx.doi.org/10.1016/j. rse.2010.01.018

Williams, B. K., J. D. Nichols, and M. J. Conroy. 2002. Analysis and management of animal populations. Academic Press, San Diego, California, USA.

Withgott, J. H., and K. G. Smith. 1998. Brown-headed Nuthatch (Sitta pusilla). In A. Poole, editor. The birds of North 
America online. Cornell Lab of Ornithology, Ithaca, New York, USA. [online] URL: http://bna.birds.cornell.edu/bna/ species/349/articles/introduction

Zabel, C. J., J. R. Dunk, H. B. Stauffer, L. M. Roberts, B. S. Mulder, and A. Wright. 2003. Northern Spotted Owl habitat models for research and management application in California. Ecological Applications 13:1027-1040. http:// dx.doi.org/10.1890/02-5084 